\title{
Inovações na intermediação entre os setores público e privado na assistência à saúde
}

\author{
Innovations in the intermediation between \\ public and private sectors in health care
}

Rosimary Gonçalves de Souza 1

Regina Cele de Andrade Bodstein 2

\footnotetext{
1 Faculdade de Serviço Social da Universidade Estadual do Rio de Janeiro. Rua São Francisco Xavier 524, Maracanã 20550-013 Rio de Janeiro RJ. rgdsouza@uol.com.br 2 Departamento de Ciências Sociais, Escola Nacional de Saúde Pública, Fiocruz.
}

\begin{abstract}
This article intends an approach with some of the changes in course in the health system, specifically the private supplier of health services, that comes maintaining along the last decades decisive weight in the conduction of the health policy. In that sense, it imports to show the different modalities under which this sector interferes the private initiative in the installment of health services, showing the more important changes in the relationship between the public and the private sectors, tending as counterpoint the context of the decades of 70 and 80 . Some of those modalities are constituted, actually, an consolidation of patterns and present tendencies since the seventies, as the section that integrates the insurance companies of health and the group medicine companies. Other, as the performance of the medical cooperatives close to the public section, they are shown as tendencies in expansion in a conjuncture of fiscal crisis of the state and the decrease of the investments in the social field.
\end{abstract}

Key words Healthcare policy, Public/private relationship
Resumo Este artigo busca uma aproximação de algumas das mudanças em curso no sistema de saúde, focalizando especificamente o setor privado prestador de serviços de saúde, que, ao longo das últimas décadas, vem mantendo peso decisivo na condução da política de saúde. Nesse sentido, importa mapear as diferentes modalidades sob as quais se insere a iniciativa privada na prestação de serviços de saúde, mostrando as mudanças mais significativas na relação entre o setor público e o privado, tendo como contraponto o contexto das décadas de 1970 e 1980. Algumas dessas modalidades se constituem, na verdade, de uma intensificação ou consolidação de padrões e tendências presentes desde os anos 70, como o setor que integra as seguradoras de saúde e as empresas de medicina de grupo. Outras, como a atuação das cooperativas médicas junto ao setor público, mostram-se como tendências em expansão numa conjuntura de crise fiscal do estado e regressividade dos investimentos no campo social.

Palavras-chave Política de saúde, Relação público/privado 


\section{Introdução}

O perfil da política social na América Latina sofre uma profunda inflexão a partir da introdução, no início dos anos 90, dos diversos planos de ajuste estrutural da economia e de reforma do Estado. O setor saúde é particularmente afetado, já que se define para os países da região uma nova agenda, em que o tema da reforma setorial e da racionalização do gasto público ganha visibilidade crescente. Apesar da variedade de contextos e das especificidades dos sistemas nacionais de saúde, algumas temáticas são comuns aos diversos países da região. Aparece com destaque nessa agenda a idéia de redução do papel do estado vis-à-vis o controle de gastos do setor saúde. Assumida como programa de governo, a reforma do estado, certamente, redefine a abrangência e o escopo das políticas sociais, com impactos mais ou menos diretos sobre o financiamento público e sobre o sistema de saúde como um todo.

No caso brasileiro, está em curso mudanças substantivas que têm como marco não só o cenário internacional da reforma e redução das funções do estado e de controle do gasto público, como também fatores internos, potencializados pela dinâmica do setor e decorrentes da implementação do Sistema Único de Saúde (SUS). O processo de descentralização, uma das principais diretrizes do SUS - considerado desde o início da década estratégia adequada, tanto para a administração e o controle dos gastos e, portanto, como para uma distribuição mais eficiente do escasso orçamento público, e visto também como caminho virtuoso para a redemocratização do sistema e a incorporação da participação popular -, sem dúvida, introduz por si só mudanças significativas.

$\mathrm{O}$ aprofundamento da descentralização em direção à municipalização da saúde, particularmente intenso a partir de 1996, abre inúmeras inovações. A municipalização redefine em grande parte a arena decisória, colocando em cena os gestores municipais, responsáveis diretos pela administração da rede de serviços e pela própria implementação do SUS.

Após uma década de implantação da reforma na saúde, a questão crucial gira em torno não só de medir o impacto real da descentralização sobre as condições de saúde da população, mas de pelo menos de se conseguir dimensionar o que de fato tem representado esse processo em relação ao incremento da eficácia e eficiência da gestão do sistema, na alocação de gastos entre o setor público e privado, nas condições de acesso, nos níveis hierárquicos e na integralidade da atenção, no desenho de novas modalidades de interseção entre público e privado enfim, no modelo de atenção em saúde.

O deslocamento do processo decisório em prol dos municípios, acarreta, portanto, diversas mudanças e alguns efeitos não esperados ou não previsíveis. Introduz, vis-à-vis a incorporação de novos atores um conjunto de incertezas, gerando uma reforma setorial cujo conteúdo, alcance e implicações são ainda de difícil avaliação. As inovações possíveis a partir da gestão descentralizada do setor e da crescente autonomia municipal configuram um dos principais desafios para os estudiosos da reforma do sistema de saúde no país, impondo novos aportes analíticos e metodologias avaliativas.

Este artigo busca uma aproximação com algumas das mudanças em curso no sistema, focalizando especificamente o setor privado prestador de serviços de saúde, que vem mantendo, ao longo das últimas décadas, peso decisivo na condução da política de saúde. Nesse sentido, importa mapear as diferentes modalidades sob as quais se insere a iniciativa privada na prestação de serviços de saúde, mostrando as mudanças mais significativas na relação entre o setor público e o privado, tendo como contraponto o contexto das décadas de 1970 e 1980. Algumas dessas modalidades se constituem, na verdade, de uma intensificação ou consolidação de padrões e tendências presentes desde os anos 70, como o setor que integra as seguradoras de saúde e as empresas de medicina de grupo. Outras, como a atuação das cooperativas médicas junto ao setor público, se mostram como tendências em expansão numa conjuntura de crise fiscal do estado e regressividade dos investimentos no campo social.

Em termos analíticos, a questão central é indagar se tais iniciativas e tendências estão submetidas à lógica de aumento da eficiência e da eficácia e dos princípios de eqüidade das ações governamentais no setor ou, ao contrário, apontam para uma privatização da oferta de serviços de saúde no país. Na verdade, trata-se de pensar na capacidade de regulação do estado em uma conjuntura de intensa disputa pelos investimentos públicos.

A complexidade do quadro reside exatamente na interação entre diversos fatores. Há de um lado, empenho na operacionalização da atual política do SUS, assentada inequivocamente de acordo com o texto constitucional de 1988 - 
no fortalecimento da esfera pública, cabendo ao setor privado um caráter complementar. Paralelamente, ocorre um movimento de autonomia da iniciativa privada em relação ao Estado, passando por um processo de profunda rearticulação interna, com ênfase na modernização tecnológica e na suposta eficácia e qualidade dos serviços, ganhando com isso espaço político e legitimidade social. A relevância que o setor privado autônomo adquire na década de 1990, potencializado pelo número expressivo de beneficiários que conquista, impõe ao governo a urgência em assumir a regulação sobre este mercado, o que vai ocorrer a partir da lei 9.656/98.

O impacto dessas inovações sobre a condução da política setorial e sobre o gasto público em saúde ainda está por ser dimensionado. $\mathrm{O}$ cenário é de bastante incerteza já que conflitos e disputas em torno dos recursos públicos, cada vez mais escassos, vêm se agravando. Entretanto é certo que o complexo arranjo entre público e privado, e a disputa pela alocação e apropriação dos recursos federais têm lugar de centralidade na orientação dada à política de saúde brasileira.

\section{Novas intermediações entre público e privado na saúde}

Ganham destaque no atual debate setorial estudos e investigações sobre as novas modalidades de relação entre público e privado na organização e oferta dos serviços de saúde, convergindo quase todos para comprovar o aumento da participação do setor privado na oferta de serviços de saúde no Brasil. No entanto, tais estudos devem ser vistos com certa reserva, já que a complexidade do quadro atual, marcado pela diversidade de contextos regionais, estaduais e municipais, e pela estrutura complexa da oferta de serviços de saúde, não pode ser avaliada de forma genérica.

$\mathrm{O}$ argumento central deste artigo é de que, no contexto atual, novas formas de relação entre o setor público e o setor privado são explicitadas, diferenciam-se sobremaneira das intermediações verificadas entre estes dois setores nas décadas de 1970 e 1980 . Essas inovações configuram-se em diferentes direções.

O primeiro caminho, assinalado anteriormente, refere-se a um gradativo processo de autonomização do setor privado em relação ao Estado, processo que começa a se delinear ainda no início dos anos 80 , e que vem a se firmar no final da década. Inicia-se um processo de mudança de hegemonia dentro do próprio setor privado. Tal contexto é dado pelo confronto entre um "setor estado-dependente" e um outro mais dinâmico e que já no seu início não mantém relações diretas com a Previdência Social (Mendes, 1996). Diluem-se assim os circuitos burocráticos que davam sustentação ao modelo médico-assistencial privatista consolidado nos anos 70, basicamente apoiado sobre a cooperação solidária - e freqüentemente prejudicial aos interesses públicos -, entre a tecnoburocracia previdenciária e os produtores privados de bens e serviços médicos.

Nos anos 90, assiste-se a um relativo recuo desse setor na celebração de contratos com o sistema público, agora representado pelo SUS. No estado do Rio de Janeiro, onde a presença das empresas médicas tem sido historicamente marcante, é visível o retrocesso deste setor, especialmente em alguns segmentos da prestação de serviço, embora quantitativamente ele continue relevante. Esse quadro nos coloca diante de uma mudança significativa no tocante à estrutura de interesses em torno da saúde. Trata-se de chamar a atenção para a tendência a um recuo significativo de um dos principais atores, com influência decisiva no perfil de organização da atenção à saúde.

É necessária uma análise sobre as motivações que levaram a esse processo, incluindo tanto o aumento na oferta de atendimento pelo poder público, especialmente pela esfera municipal no que se refere aos serviços sem internação quanto o desinteresse desse segmento do setor privado em manter os convênios. Dois fatores simultâneos parecem influir nessa mudança de cenário. De um lado, as baixas remunerações pagas pelo SUS, e de outro uma possibilidade mais lucrativa de investimentos no segmento da chamada medicina de grupo e de seguros-saúde.

Observa-se que a tendência é de se descredenciarem do SUS aqueles grupos privados com capacidade de investimento e de modernização, permanecendo vinculado ao sistema público, as empresas médicas menos capitalizadas e mais atrasadas do ponto de vista gerencial e tecnológico.

A entrada em cena de novos atores vinculados à esfera municipal, com a descentralização político-financeira em curso, é um fator que contribui para a recomposição do setor privado no interior da arena política setorial. Com a transferência da responsabilidade da gestão para estados e, principalmente, para os municí- 
pios, ocorre uma relativa pulverização dos espaços de negociação e disputa de interesses em torno da saúde. Tal realidade difere do modelo implementado nas décadas anteriores, onde grandes arranjos político-clientelistas entre o setor privado contratado e a tecnoburocracia ocorriam preferencialmente no espaço circunscrito à esfera federal.

Mesmo o esquema de fraudes no pagamento de procedimentos à iniciativa privada pelo extinto Inamps teve que se adequar aos novos tempos e às novas formas de controle e de auditoria. Esse esquema foi alvo de inúmeras denúncias e, diante de uma conjuntura de grave crise econômica, responsabilizado, em parte, pela falência do sistema previdenciário.

Os anos 90 trazem para o centro do debate, como nos referimos anteriormente, o tema da reforma do Estado e da eficiência das ações governamentais - imperativo numa conjuntura de déficit público e de ajuste estrutural da economia -, em que a busca de uma maior racionalidade no gerenciamento dos recursos públicos é crucial. No setor saúde, tal conjuntura coincide com a redefinição dos espaços decisórios e dos atores: o executivo local, os conselhos de saúde, as câmaras técnicas, as comissões intergestoras (bi e tripartites), a esfera legislativa, entre outros. Assim, de um lado, há uma limitação de recursos e de outro novos temas e prioridades na agenda pública vis-à-vis a redefinição de novos arranjos setoriais. Alguns grupos mostram-se explicitamente empenhados em não ser identificados com o esquema de fraudes anterior.

A conjugação desses fatores permite que, em certos casos, se constituam sistemas de saúde locais, com maior grau de eficácia e maior controle, inclusive sobre procedimentos realizados pelas empresas médicas contratadas. Isso define claramente uma tendência dentro da política de saúde, já que o novo desenho institucional, comporta inúmeras modalidades de organização e gestão, conforme o arranjo político em cada contexto local.

Importa dentro deste cenário identificar uma postura da esfera federal, representada pelo Ministério da Saúde, bem como dos técnicos do setor, de "premiar" as melhores concepções e práticas na atenção à saúde, dando visibilidade às experiências bem-sucedidas. Isso se torna vital diante do desafio de dar respostas concretas às complexas necessidades sanitárias do país, driblando, inclusive, as recorrentes restrições de ordem financeira. São exemplos os progra- mas Médico de Família (Niterói) e Saúde da Família (Ceará), que, com ajustes e adaptações, hoje têm o status de "modelo" para a saúde do país, mediando o debate sanitário nacional e ocupando lugar estratégico na política do Ministério da Saúde.

Ora, o que está em jogo é a necessidade de difundir experiências e programas estratégicos para a reorganização da política de atenção básica, principalmente nas regiões mais pobres do país e com maior déficit na oferta de serviços de saúde. Importa pontuar a indução pelo governo federal de uma política claramente incentivadora de uma reestruturação e favorecimento da atenção básica a cargo dos municípios, como demonstram a rápida implementação dos programas de Saúde da Família (PSF/94) e o Piso de Atenção Básica (PAB/97).

O próprio aperfeiçoamento do jogo democrático dá visibilidade crescente ao emprego dos recursos públicos, principalmente nos setores $\mathrm{e}$ segmentos sociais mais vulneráveis. Verifica-se uma busca pelos gestores municipais de políticas capazes de impactar senão as condições de saúde, pelo menos de melhorar o atendimento médico prestado pela rede local do SUS, e, portanto, buscando estratégias que em curto prazo tragam soluções e garantam claros dividendos políticos. A ineficácia do modelo médico-assistencial privatista do período anterior continua sendo alvo de intensas críticas, balizadas pela constatação de que boa parte do razoável montante de recursos aplicados não era revertida quer em uma melhora na oferta de serviços, quer na organização mais eficiente da rede e muito menos em melhores níveis de saúde. Ao contrário, ou se perdia nos meandros da administração pública ou era apropriado por grupos privados com a aquiescência do governo.

Há uma clara tendência entre os atuais gestores de imprimir maior transparência ao processo de credenciamento de empresas médicas, bem como um monitoramento (mais quantitativo que qualitativo) dos serviços contratados, ameaçando, em alguns casos, as relações promíscuas entre o público e o privado. Os registros e atas dos Conselhos Municipais de Saúde, pelo menos daqueles mais atuantes, atestam tal fato. $\mathrm{Na}$ medida que cada novo serviço a ser credenciado é objeto de debate pelos conselheiros, em que se explicita a necessidade de sua contratação, as razões pelas quais a esfera pública não pode provê-lo, assim como estratégias de avaliação sistemática da prestação do serviço (nem sempre implementada), coloca, sem dúvida, pa- 
ra os gestores novas responsabilidades e compromissos. Aqui fica estabelecida, como já nos referimos, uma prática distinta das intermediações de cunho clientelista do passado, à medida que o processo de contratação de serviços terceirizados passa em maior ou menor escala por uma esfera de decisão coletiva.

Diante disso, a posição dos grupos privados (especialmente aqueles que mantiveram ao longo de anos convênios com o extinto Inamps) orienta-se pela estratégia de desqualificar a capacidade da esfera pública na implementação do SUS, em virtude da proclamada ineficiência gerencial do estado. A estratégia pauta-se então não em críticas diretas à nova política do setor saúde e, muito menos, em crítica e negação aos princípios da universalidade e da eqüidade, vinculados aos ideais democráticos e de justiça social tão propalados nos dias correntes. Ao contrário, os empresários, especialmente aqueles que tiveram seus interesses fragilizados pelas propostas do SUS, apostam, sobretudo, na inoperância do novo formato de gestão em vigor bem como na histórica dificuldade de regulação do Estado brasileiro.

\section{O setor privado autônomo: mecanismos regulatórios e interações com a esfera pública}

Uma outra modalidade sob a qual se apresenta o setor privado de saúde no Brasil é aquela rotulada de "setor privado autônomo" (Reis, 1997) ou “atenção médica supletiva” (Mendes, 1996), que busca consolidar seus interesses com autonomia e independência em relação ao Estado, já que este não participa de seu financiamento direto. Importa assinalar, de início, que o crescimento desta modalidade de prestação de serviços aparece como um efeito não previsto nos marcos da reforma sanitária e no contexto de aprovação do SUS, ainda no final da década de 1980 , bem como no decorrer de sua implementação a partir do início dos anos 90.

O setor integra as seguradoras de saúde, as cooperativas médicas e as empresas de medicina de grupo. Segundo levantamento do Ipea, o setor compreende mais de mil empresas, movimenta cerca de US\$14,8 milhões por ano, o que equivale a (2,6\% do PIB) e cobre aproximadamente $27 \%$ da população do país (Visor Ipea, 1998). Dados mais recentes vêm apontando uma queda dessa proporção em função da recessão chegando a um patamar de $16 \%$ de po- pulação coberta, mas tais dados não são precisos na interpretação de Bahia (2001), considerando o tamanho da amostra e os critérios de seleção dos entrevistados. Para a autora, a precariedade e imprecisão dos dados sobre o subsetor da assistência médica suplementar no Brasil tornam mais tortuosos os caminhos para a interpretação da dinâmica interna desse segmento e suas inter-relações com a agenda governamental mais ampla na área da saúde.

O crescimento vigoroso da assistência suplementar, que se deu ao longo das duas últimas décadas, se deve, principalmente, à universalidade proposta pelo SUS. Isto é, tal crescimento mantém uma relação direta com a expansão da clientela do sistema público a partir da afirmação do direito universal à saúde em 1988 e do estrangulamento da oferta de serviços públicos de boa qualidade. A conjuntura de incerteza quanto aos rumos da reforma do Estado, a crise econômica e a descontinuidade e mesmo regressividade dos investimentos sociais - quer na manutenção, quer na ampliação de serviços - explicam em grande parte este aumento de clientela vis-à-vis à expansão acelerada deste setor.

O aumento de clientela deste setor não deve ser imputado somente à perda de qualidade do setor público, efeito perverso da universalização do sistema de saúde em uma conjuntura de restrição dos investimentos sociais. A nosso ver, é necessário considerar o significativo aumento da urbanização em todo o país (flagrante nas duas últimas décadas) e, associado diretamente a esse processo, o considerável aumento da demanda por serviços médico-sanitários e por outros bens e equipamentos públicos.

É necessário perceber que outros fatores interferem no acesso e na utilização de serviços de saúde. A garantia e a segurança de possuir um plano de saúde não pode ser ignorada, já que passa a fazer parte da demanda social e das aspirações dos diversos segmentos da sociedade brasileira, que conseguem alguma ascensão social. Essa aspiração geral por inclusão no setor médico supletivo, é bom que se diga, independe da adequação, extensão ou até mesmo da qualidade do serviço prestado.

À parte da discussão sobre os segmentos que compõem a clientela dos planos de saúde - se é constituída basicamente da classe média e de trabalhadores das grandes empresas, como se sabe, os planos de saúde, já em fins dos anos 80 , compunham a agenda de negociação dos sindicatos de operários e a pauta de reivindicação dos 
trabalhadores mais bem organizados -, importa observar que a visão comum é de que o setor público de saúde é associado à ausência de médicos e de equipamentos, à espera excessiva, ao desprezo pelas necessidades individuais, ao descuido com as instalações e conforto da clientela, fatores aos quais a área privada responderia com eficiência.

O setor privado autônomo, genericamente conhecido como o setor vinculado aos "planos de saúde”, aparece, em contrapartida, representado no imaginário social, como referência assistencial de melhor qualidade frente aos riscos e imprevistos dos agravos à saúde. Estratégias de marketing veiculadas através da mídia, sem dúvida, contribuem diretamente para a divulgação da concepção de maior eficiência da atenção médica supletiva, enfatizando sua rapidez e resolutividade. Inclusive, convém salientar que é latente entre os não-usuários dos serviços prestados por essas empresas médicas (os sem-planos de saúde, portanto) o sentimento de exclusão dos benefícios que o arsenal tecnológico do campo médico pode hoje oferecer. As campanhas publicitárias dão ênfase exatamente a estes dois pontos: a) facilidade e comodidade no acesso aos serviços em qualquer lugar e a qualquer hora, e b) disponibilidade/acessibilidade aos mais modernos equipamentos de diagnóstico e terapia, sem demora e sem enfrentar longas filas, fenômeno tão comum no setor público.

O contraponto a esse marketing vem, de certo modo, da quantidade de ações que tramita na justiça pleiteando reparação de danos causados pela má qualidade ou pela ausência de atendimento aos usuários da atenção médica privada. A gama de ações e de recursos judiciais é de tal ordem que fomentou um amplo debate na sociedade, cuja direção apontou para a necessidade de uma efetiva regulação do Estado sobre o mercado dos planos de saúde.

Após muitos conflitos e impasses no âmbito legislativo foi promulgada, em junho de 1998, a lei que regulamenta o mercado, estabelecendo parâmetros básicos para a prestação de serviços de saúde, ampliando cobertura e direitos, incluindo doenças antes não assistidas e regras para o cumprimento de carências, entre outras providências (ver lei 9.656/98).

O tempo de vigência da lei e suas constantes alterações ainda não permitem conclusões mais definitivas sobre sua capacidade concreta de balizar as relações empresa/clientela e de proteger os usuários. Entretanto, é certo que diferente do que ocorreu até recentemente, quando o setor não tinha qualquer regulamentação, a nova legislação permite que, pelo menos, novos mecanismos se interponham à selvageria do mercado.

Acresce-se a isso um atributo particular da clientela do mercado de serviços privados: o grau de escolarização, de consciência de seus direitos, e sua capacidade de vocalizar demandas. Nesse aspecto, difere fundamentalmente da média dos usuários do SUS que, por motivos bem conhecidos, têm muito mais dificuldade em formular e dar visibilidade às suas demandas e reivindicações e, que até há pouco tempo consideravam o atendimento público gratuito quase um favor prestado pelo governo.

O quadro que se desenha permite antever um aumento da pressão exercida sobre o Estado pelos usuários dos planos de saúde e das associações de defesa dos consumidores, no sentido de que seja exercida uma efetiva fiscalização sobre esse mercado, aperfeiçoando ou ampliando os dispositivos legais já existentes. Uma resposta satisfatória a essa "pressão" é difícil se se tem em vista a baixa capacidade regulatória do Estado brasileiro e a morosidade do nosso sistema jurídico.

Cabem, portanto, duas ordens de reflexão a propósito dos efeitos da regulamentação dos planos e seguros privados de saúde. A primeira diz respeito a um certo "alívio" do setor público a partir da nova legislação, ao obrigar as empresas médicas a arcarem com o tratamento das doenças crônicas, com os procedimentos de alta complexidade e, portanto, de alto custo, que sempre recaíam sobre o sistema público. De outro lado, esse alívio é relativo, já que novos encargos e responsabilidades podem acabar por encarecer demais os planos, fazendo com que a clientela de menor poder aquisitivo volte a utilizar a rede pública. Mas, sem dúvida, já é visível e tende a se intensificar "a queda de braço" entre o poder público e as empresas responsáveis pelos planos e seguros privados.

Hoje em dia, a questão crucial para o setor e para a implementação e preservação dos princípios de eqüidade do SUS reside na capacidade efetiva de regulação pública e na pactuação dos critérios em que se dá a articulação entre o sistema público e o suplementar na prestação do cuidado médico. Isto é, quanto mais precário e ineficiente o controle social e a capacidade de regulação pública, maior a autonomia desse setor privado. Dada a impossibilidade do sistema público de prescindir do mercado privado de saúde, o debate gira em torno do questionamen- 
to sobre o quantum de autonomia deve manter este mercado em relação ao Estado.

Para Reis (1997), os mecanismos tradicionais e os diferentes incentivos que o Estado têm fornecido a este setor vêm consolidando suas bases de sustentação e permitindo mesmo sua expansão. O principal fator de crescimento desta modalidade de prestação de serviço de saúde foi garantido através da renúncia de arrecadação fiscal por parte do Estado, mecanismo indireto, porém, claramente, de incentivo a formação dessas empresas, evidenciando a relativa dependência deste segmento em relação ao Estado.

O impacto dessa modalidade de relação entre público e privado sobre o gasto público no setor saúde ainda precisa ser mais bem avaliado. Mas o fato é que este complexo arranjo vem se tornando cada vez mais intrincado, impondo a necessidade de análises mais precisas, capazes de captar suas múltiplas implicações.

\section{As cooperativas médicas no cenário atual}

O terceiro filão explorado pela iniciativa privada na prestação de serviços de saúde compreende as chamadas cooperativas médicas, que tiveram crescimento vigoroso ao longo desta última década. Tais entidades, diferentemente da assistência médica "autônoma", mantêm uma relação de dependência direta com o Estado, já que prestam serviços às instituições públicas de saúde, embora não exclusivamente.

Os contratos celebrados entre as cooperativas e o sistema público, representado na sua maioria pelas prefeituras, prevêem que as cooperativas mantenham sob sua responsabilidade o recrutamento, seleção e administração de profissionais que atuarão em unidades públicas.

A regulamentação do SUS pressupõe prioridade na prestação de serviços por cooperativas e entidades sem fins lucrativos. Nessa brecha legal é que as cooperativas médicas se organizam e se expandem. Esse processo é impulsionado pela nova distribuição de responsabilidades no interior da política de saúde com ênfase na ação municipal. É exatamente diante da precariedade da oferta de serviços públicos e da fragilidade da organização administrativa da esfera municipal, vis-à-vis a fragilidade dos investimentos na saúde que as cooperativas se fortalecem. Os profissionais cooperados representam para alguns municípios e sistemas locais um supor- te importante para o funcionamento dos serviços e da atenção à saúde, notadamente naquelas áreas onde o poder público, por diversos motivos, não consegue atrair ou fixar o profissional de saúde.

No estado do Rio de Janeiro essa experiência vem se disseminando entre os diversos municípios. Importante notar que entre esses municípios estão alguns de grande porte como a capital, Nova Iguaçu e Duque de Caxias. Seja na reativação de unidades básicas e maternidades na periferia, como no caso de Duque de Caxias, seja na reestruturação de grandes hospitais, como o da Posse em Nova Iguaçu - o primeiro do Estado a funcionar a partir de 1995 com cooperativa -, e o Lourenço Jorge no Rio de Janeiro, a lotação de profissionais cooperados, principalmente médicos, tem sido a principal estratégia adotada pelo gestor municipal para manter a rede e os serviços públicos em funcionamento.

A entrada das cooperativas médicas no sistema público de saúde tem sido objeto de intensa polêmica. Polêmica alimentada pela própria complexidade da política de saúde, que tem a sua frente o desafio de dar respostas rápidas e emergenciais a questões de grande amplitude e de grande apelo popular e eleitoral. Ao mesmo tempo, os gestores locais têm de contemplar, e mesmo "harmonizar", interesses diversos e até contraditórios, fruto da descentralização e dos novos arranjos políticos locais.

Do ponto de vista dos gerentes, a contratação das cooperativas representa a possibilidade de garantir um mínimo de eficiência e resolutividade aos serviços e da rede pública, na medida que tanto o processo de admissão quanto de demissão de profissionais torna-se mais ágil. Por outro lado, apresenta-se como um problema para os gestores locais a não-vinculação do profissional cooperativado com a instituição em que atua, dada a intensa rotatividade e mesmo precariedade desta relação empregatícia. Isso freqüentemente resulta no não-envolvimento desse profissional com os principais programas de saúde pública, com as demandas da unidade, com os usuários e, por extensão, com a comunidade local. É recorrente no depoimento dos gestores, a não-inclusão do profissional de cooperativa nos programas de treinamento e reciclagem. De forma geral, tais profissionais não fazem parte das equipes dos programas de saúde desenvolvidos rotineiramente pelas instituições públicas.

Essas questões têm um impacto direto sobre a qualidade da assistência, mas sua avaliação 
é bastante complexa. É preciso entender que em situações emergenciais de déficit gritante de profissionais, e diante de situações como de desativação de leitos e fechamento de serviços e unidades de saúde, a contratação de profissionais cooperativados torna-se para os gestores locais uma possível solução. Em outros contextos nos quais o nível de oferta e a organização dos serviços são melhores estruturados, provavelmente essa modalidade de contratação cria mais problemas do que soluções, haja vista os conflitos e insatisfações trabalhistas que suscita. Nesse sentido é importante ter em mente que, diante da descentralização e municipalização acelerada, as prioridades e os desafios são comumente definidos localmente, implicando uma variedade de situações e contextos.

Um dos grandes desafios que o setor enfrenta hoje passa pela reformulação ou definição de um novo modelo assistencial em saúde. Está em jogo entre outras coisas medidas e ações concretas que potencializem a famosa integralidade da atenção à saúde, preconizada desde o início da criação do SUS. A idéia é superar a dicotomia entre ações curativas e preventivas, garantindo o direito da população a um atendimento de qualidade em todos os níveis da atenção em saúde. Está em discussão também a questão da promoção à saúde onde o setor saúde é um entre os diversos setores da administração pública responsáveis pela saúde da população.

A contratação das cooperativas médicas certamente é uma solução emergencial para suprir um déficit de consultas médicas e ambulatoriais em geral, que nada contribui para o desenho de um modelo de atenção mais resolutivo e mais eficiente na promoção e prevenção dos agravos à saúde, apesar da significativa expansão da oferta verificada após a entrada das cooperativas. A presença das cooperativas, principalmente nas áreas periféricas dos grandes centros urbanos, áreas essas com enorme demanda e baixíssima oferta, representa a possibilidade de reorganização da rede pública e de ampliação do acesso aos serviços médicos - assistenciais em geral. Polêmicas e tensões políticas à parte, os dados de produtividade das secretarias municipais de saúde onde as cooperativas atuam demonstram claro aumento de cobertura das ações de saúde, com nítida repercussão sobre o grau de satisfação da clientela. É certo que o indicador (satisfação da clientela) é por si bastante subjetivo e sujeito a manipulações, o que contudo não o invalida se pensarmos na precariedade ou ausência quase total de cobertura assistencial, antes da introdução dos profissionais cooperativados.

O funcionamento da rede de saúde através da contratação de cooperativas torna-se também, em momento de crise financeira, uma solução para as vultuosas demandas dirigidas aos governos locais, atendendo a uma dupla função: 1) a reativação de unidades de saúde gera dividendos políticos incontestáveis e; 2 ) a própria provisoriedade desses contratos permite às burocracias municipais lidarem com as descontinuidades da receita municipal para a área.

As dificuldades interpostas à política de financiamento do setor parecem incompatíveis com os custos advindos da contratação de um número expressivo de novos profissionais estatutários e, além do mais, em alguns casos, com remuneração acima da média atual do setor público, realidade dos médicos cooperativados hoje. Tal estratégia geraria despesas fixas das quais a administração municipal não poderia desvencilhar-se em caso de necessidade.

A entrada das cooperativas no setor público tem sido questionada também pelos próprios conselhos de medicina, ator político relevante no contexto setorial que vem colocando em discussão a dimensão ética envolvida nesse processo, mobilizando inclusive seus departamentos jurídicos para dar suporte a tais indagações, como de resto questionou os contratos de terceirização de hospitais públicos em vigor no estado do Rio entre 1996 e 1998. Esses contratos foram desarticulados em 1999 devido à eleição de uma nova coalizão política para o governo do estado.

$\mathrm{Na}$ ótica das entidades de fiscalização do exercício da prática médica, há com o sistema de cooperativização das instituições uma fragmentação das responsabilidades éticas e civis devido à natureza jurídica das cooperativas, cuja dinâmica de funcionamento não permite, ou pelo menos dificulta muito, a fixação e capacitação dos profissionais, diferente da rotina usual das instituições públicas.

Nestes termos, é flagrante a ambigüidade em que se encontram as entidades de representação médica que, se por um lado, identificam e questionam as diversas irregularidades do exercício da prática médica através do modelo de cooperativas (como restrição aos direitos trabalhistas, não-pagamento de pró-labore aos médicos, entre outros), por outro, representam novos postos de trabalho para a categoria, restritos devido a pouca oferta de vagas via concurso público. 


\section{Os novos convênios entre grandes hospitais públicos e planos de saúde}

No quadro atual, identifica-se ainda uma outra tendência nas relações entre o setor público e o setor privado, dada pelos novos convênios estabelecidos entre os "planos de saúde" e hospitais públicos, os quais passam a vender para aqueles serviços de alta complexidade. Os convênios e contratos se dão notadamente com os hospitais universitários, mas também em menor escala com grandes hospitais especializados.

No Rio de Janeiro, empresas firmaram recentemente convênios para prestação de alguns serviços na área de cardiologia: com o Hospital Universitário Clementino Fraga Filho (UFRJ), com o Hospital Universitário Pedro Ernesto (UERJ) e, para a realização de cirurgias, com o Hospital de Traumato-Ortopedia (Ministério da Saúde), entre outros. Tal tendência ainda está longe de se configurar um expediente já consolidado. Entretanto, o debate em torno do tema demonstra claramente o potencial de conflitos em torno da iniciativa.

Para os hospitais significa o benefício de recursos extras, em meio a uma crise financeira séria, provocada pela queda acentuada nos valores do repasse de recursos federais nos últimos anos. Assim, para os que estão à frente da gestão dessas instituições, os contratos com a área privada permitem maior autonomia gerencial na medida que os recursos públicos deixam de ser a única fonte de financiamento, ainda que continue a ser a principal.

Por outro lado, ao assumir como clientela os usuários do serviço privado, os hospitais públicos correm o risco de reduzir ou limitar o atendimento a sua clientela primordial, já que por falta de investimentos não ocorreu uma ampliação no número de leitos. Ou seja, os atendimentos e o número de leitos públicos, como é notório, são sempre inferiores à demanda. Além disso, o valor dos repasses federais fica sempre aquém do aumento constante dos custos hospitalares, pairando a ameaça de fechamento dos já precários leitos e atendimentos públicos especializados.

$\mathrm{O}$ argumento utilizado para justificar os contratos com o setor privado - a provisão de mais recursos para fazer face a esse quadro e, assim, garantir e/ou ampliar a oferta -, deve ser analisado com cuidado. Corre o risco de se transformar em um fator de agravamento da crise, na medida que, na prática, funcione como um incentivo perverso de restrição na oferta de leitos e atendimentos públicos. A distorção, como nos referimos, só seria minimizada com um "aumento real" no total de ações prestadas por esses hospitais, o que, a curto e médio prazos, parece difícil de ocorrer, já que não há indícios de aumento da capacidade instalada desses serviços.

Reforça-se, então, a importância das instâncias regulatórias no processo de venda de serviços pela esfera pública ao setor privado. Primeiro, no que se refere à natureza e dimensões desses convênios de forma a não se incorrer no equívoco de colocar a serviço da área privada a estrutura pública de alta complexidade e de serviços hospitalares em geral, tornando-os inacessíveis à clientela do SUS.

Os novos convênios entre o setor privado e os hospitais públicos de alta complexidade ganham relevância diante do conjunto de medidas de regulamentação dos planos de saúde, exigindo, entre outras coisas, que as intervenções de alto custo constem e sejam explicitadas no contrato firmado entre empresa e usuário. Antes da entrada em vigor da lei 9.656/98, cada empresa oferecia um elenco de serviços que melhor lhe aprouvesse, cabendo ao potencial cliente (contratante) aceitá-lo ou não. Assim, os procedimentos de alto custo eram quase que exclusivamente custeados pelo setor público, inclusive para aquele segmento da clientela vinculado à medicina privada. Isto é, dado o volume de investimentos exigidos e seu alto custo, serviços de alta complexidade não estavam incluídos na maioria dos planos de saúde. Para o conjunto das empresas médicas, com algumas exceções, não há interesse, dado o volume de investimentos prévios, em custear ou expandir a oferta dos serviços.

Devido ao alto custo representado pela incorporação de equipamentos biomédicos e de profissionais especializados, a oferta desses serviços é sempre problemática. Neste cenário, a regulamentação do mercado privado de saúde, mesmo que voltada para a defesa dos interesses da clientela e dos usuários, é por si só complexa e polêmica. Cabe ao setor assumir sua parcela de responsabilidade no financiamento da medicina de alto custo, bem como na cobertura do tratamento das doenças crônicas e infecto-contagiosas. Porém, é preciso deixar claro, se as restrições e exigências impostas ao setor privado forem excessivas, a oferta acabará sendo ainda menor e a clientela prejudicada. Esse é o dilema de qualquer política de regulação; dilema este normalmente desconsiderado pelos grupos e 
setores que defendem a responsabilidade do setor público com o sistema de saúde em geral. Isto é, mecanismos regulatórios, é impossível ignorar, podem desencadear efeitos perversos e indesejáveis, acabando por prejudicar os interesses daqueles que inicialmente procuravam se defender.

Com efeito, a posição dos altos escalões do setor saúde diante dessa nova relação de compra e venda de serviços e, portanto, entre o sistema público e o sistema privado, tem se mostrado extremamente dúbia. Apesar da complexidade da questão, iniciativas no sentido de firmar regras para o estabelecimento de tais contratos e para dificultar que eles se proliferem dentro da rede pública, parecem ainda pouco efetivas. Sem qualquer parâmetro regulador, fica a critério das próprias partes envolvidas hospitais e empresas privadas - a delimitação da abrangência e cumprimento dos convênios.

Convém chamar a atenção para o fato de que não existe qualquer controle por parte do poder público sobre a aplicação dos recursos provindos dos contratos, o que pode ser agravado já que essas grandes instituições de saúde estão fora da instância da gestão municipal. Como se sabe, os serviços de alta complexidade permaneceram, mesmo depois da descentralização da rede pública, sob a gestão federal ou estadual, já que funcionam como referência regional.

Coerente com o discurso da reforma do Estado e da busca de maior eficiência na gestão pública, dissemina-se a idéia de que é necessário garantir maior autonomia e flexibilidade às unidades de saúde. Assim, o poder público, na verdade, fecha os olhos para as soluções e medidas encontradas pelas próprias instituições para gerir internamente os déficits e restrições orçamentárias.

Não obstante todas as distorções e riscos inerentes à complexidade do processo e à diversidade de experiências, é certo que a sociedade e o setor saúde, em particular, dispõem de mecanismos mais efetivos de regulação e estão cientes da sua importância e centralidade na defesa dos interesses públicos. Da mesma maneira, as críticas e denúncias feitas ao modelo médico assistencial privatista (Mendes, 1996) - consolidado na década de 1970 e famoso por sua ineficiência e incapacidade de promover eqüidade na atenção à saúde - são hoje referências fundamentais para a gestão pública e para as organizações da sociedade. Identifica-se, de modo geral, um cenário de maior transparência e responsabilidade na administração dos recursos e instituições de saúde, reflexo do processo de reforma setorial, que criou e incentivou a formação de instâncias de controle social. Isto é, o constante exercício democrático e o aperfeiçoamento das instâncias de controle social, como os conselhos de saúde, sem dúvida, vêem tendo uma enorme influência sobre o aumento da capacidade de gestão e de regulação do setor público.

Os interesses do setor privado e os acordos com o setor público, ao que parece, são hoje mais explícitos e transparentes, ainda que em certas circunstâncias e lugares o setor tenha acesso privilegiado à agenda e à tomada de decisão setorial. Entretanto, há evidências de que a maioria dos acordos é firmada agora de maneira mais transparente, ao contrário do que ocorria no período autoritário. A própria descentralização - com a mudança nos processos decisórios, com a criação de novas esferas de negociação (a tripartite e a bipartide) e com a proliferação dos Conselhos de Saúde - impõe uma nova dinâmica setorial, não mais restrita ao circuito da burocracia central e das empresas médicas, sem qualquer possibilidade de controle da sociedade.

Essa tendência aqui discutida pode ser exemplificada pela divulgação da notícia da inauguração (7/7/99) do novo Centro de Tratamento Intensivo do serviço de cirurgia cardíaca do Hospital Universitário Pedro Ernesto, unidade da UERJ, considerado um dos mais modernos do país em assistência cardiorrespiratória, equipado com tecnologia de última geração e que, além de reformado, passará a oferecer assistência também a pacientes conveniados a planos de saúde. A reportagem enfatiza que o atendimento será o mesmo realizado aos pacientes do SUS e que haverá uma fila diferenciada para as cirurgias. Ora, fica claro, no exemplo, uma preocupação dos grupos que estão à frente desses contratos em enfatizar o caráter primordialmente público das instituições e só residualmente voltado para a assistência privada. A justificativa é necessária inclusive porque tais inovações têm sofrido muitas críticas dentro e fora das instituições de origem, deixando muito claro seu caráter polêmico.

Não se pode deixar de considerar a intensa e tradicional relação da categoria médica com o ideário da medicina liberal e a defesa intransigente do caráter privado da prestação de serviços de saúde, seja na relação médico-paciente, seja na condição de empregado ou proprietário de clínicas e hospitais. Como é notório, um alto percentual da categoria médica possui con- 
tratos com os próprios "planos de saúde". Ou seja, essa imbricação entre interesses públicos e privados, no que diz respeito à categoria médica, antecede e ocorre fora do âmbito do SUS, tornando ainda mais problemática e difusa a linha divisória entre o público e o privado dentro dos hospitais públicos contratados pelas empresas para atender seus usuários. Toda essa discussão sinaliza, no mínimo, o potencial de conflito das inovações e chama a atenção para a possibilidade de distorções na disputa e alocação dos recursos assistenciais entre clientela privada e clientela do SUS, no interior das instituições públicas.

Essa nova modalidade de inter-relação entre a estrutura pública e estrutura privada constitui-se ainda, pelo pouco tempo de vigência dos contratos, um mecanismo não-consolidado na política de saúde. É certo, entretanto, que diante das restrições orçamentárias e as dificuldades na administração do SUS essas questões estarão cada vez mais presentes na agenda pública, embora não se venha verificando uma expansão tão acentuada de tais convênios desde aqueles que se firmaram inicialmente.

No caso dos hospitais vinculados às universidades federais, os convênios com os "planos de saúde" coincidem com as diretrizes do projeto de autonomia universitária anunciado em abril de 1999 pelo Ministério da Educação, que incentiva a busca de outras fontes de receita, além dos repasses do ministério. O debate em torno da autonomia universitária é acirrado, confrontando diversos grupos vinculados à estrutura universitária pública, e levanta o questionamento sobre a capacidade de sobrevivência das instituições, diante da redução do financiamento público. O debate está apenas começando, já que o custeio dos hospitais universitários tem um peso enormemente no orçamento atual das universidades.

Qualquer alteração no cenário (manutenção, expansão ou, por outro lado, retrocesso desses convênios) dependerá, por certo, do jogo político e da pactuação entre os diferentes atores e interesses envolvidos. Assim, se por um lado, a crise de financiamento do setor público provoca e induz inovações no terreno da captação de recursos para custeio de suas atividades, por outro, as forças sociais presentes na arena setorial - seja em nome de interesses corporativos, seja em defesa dos interesses públicos de forma ampla - têm demonstrado grande capacidade de influenciar a agenda governamental, evidenciando a imprevisibilidade dos resultados.

\section{Considerações finais}

O investimento público no campo da saúde afasta-se cada vez mais de um certo ideal universalista, aproximando-se de uma estratégia de intervenção focal, priorizando determinadas clientelas em função da situação de risco ou de vulnerabilidade em que vivem. Embora seja polêmico se esta estratégia provoca mais ou menos eqüidade, o fato é que a eleição de determinados grupos sociais e/ou regiões está baseada exatamente na argumentação da necessidade de diminuição das desigualdades. E esse argumento está cada vez mais freqüente na agenda de decisão das políticas sociais.

Tais medidas são inclusive potencializadas pelo próprio debate, presente hoje no país, sobre a incompatibilidade entre o desenvolvimento econômico alcançado e os altos índices de pobreza que ainda ostentamos, resultantes da colossal desigualdade social que atravessa a sociedade brasileira. Deste modo, torna-se cada vez mais consensual o imperativo de se implementarem políticas ativas voltadas aos mais pobres e/ou vulneráveis biologicamente.

Com isso, legitima-se progressivamente a segmentação de clientelas, legitimando, portanto, o lugar ocupado pelo setor privado "autônomo" no setor saúde, a quem cabe o atendimento das necessidades de saúde de quem pode pagar pelo atendimento, seja porque tais segmentos preferem, de fato, a lógica assistencial do setor privado, seja porque não se constituem em grupo prioritário para as ações e para os investimentos sociais do governo.

O debate e a oposição até então acirrados em torno da perda de qualidade do sistema público em função da retirada dos setores de classe média, com sua migração para o setor privado autônomo, estão sendo substituídos por um discurso que assume a necessidade de imprimir maior eficiência e efetividade à gestão do sistema público. Os desafios setoriais não são poucos, já que a demanda por assistência médicosanitária é crescente e compreende aproximadamente $2 / 3$ da população do país. Isto que dizer que o SUS tem que dar conta de atender a uma população estimada em 130 milhões de pessoas, desafio enfrentado por poucos países no mundo (Visor Ipea, 1998).

Com efeito, o setor privado prestador de serviços de saúde soube acomodar-se às novas regras estabelecidas no interior da política de saúde no decorrer dos anos 90. O SUS, conferindo um caráter complementar à iniciativa 
privada no funcionamento do sistema, deixou evidente que o sistema não podia prescindir desse setor. Este por sua vez foi capaz de se adaptar à nova situação, desviar seus investimentos para outras esferas da prestação de serviços de saúde além dos convênios tradicionais com o sistema público, reafirmando sua posição de sujeito político relevante no contexto setorial.

O capital privado na saúde encontra-se hoje diversificado em diferentes frentes de atuação conforme descrevemos aqui. Seja através dos chamados planos de saúde, seja das cooperativas que mantêm convênio com os sistemas locais ou ainda, através da manutenção de convênios com o SUS. É certo que este segmento, visto no seu conjunto, mantém enorme vitalidade, capacidade de mobilização e de adaptação às mudanças nas regras do jogo.

\section{Referências bibliográficas}

Almeida C 1998. O mercado privado de serviços de saúde no Brasil: panorama atual e tendências da assistência médica suplementar. Ipea/PNUD, Brasília, novembro.

Bahia L 2001. O mercado de planos e seguros de saúde no Brasil: tendências pós-regulamentação. In Barjas $\mathrm{N}$ e Giovanni G. Brasil: radiografia da saúde. Unicamp, Campinas.

Barros E 1997. Política de saúde no Brasil: a complexa tarefa de enxergar a mudança onde tudo parece permanência. In Canesqui AM (org.). Ciências sociais e saúde. Hucitec/Abrasco, São Paulo.

Cohn A \& Elias P 1999 (org.). O público e o privado na saúde - O PAS em São Paulo. Cortez/Cedec, São Paulo.

Draibe SM 1999. As políticas sociais nos anos 90. In Baumann R (org.). Brasil: uma década em transição. Ed. Campus, São Paulo.

Iglehart JK. The American Health Care System - Managed Care. The New England Journal of Medicine, v. 327 (10):743-47.
A cena setorial hoje expõe, como vimos, um arranjo complexo onde convivem diversas tendências e novas modalidades de relação entre público e privado, mas também entre os parceiros dentro do próprio setor público. Com a consolidação do processo de descentralização nos anos 90, definem-se experiências locais que inauguram e põem em prática diversos modelos de gestão, com maior ou menor incorporação do setor privado, bem como formas diferenciadas de controle sobre os serviços prestados pela estrutura conveniada.

Buscou-se assim, nesta análise, dimensionar as atuais tendências nas relações entre a esfera pública e a iniciativa privada no campo da saúde, analisando o conteúdo das inovações em curso, tendo por referência a propalada capacidade de inovação tecnológica e de conquista de novos mercados, empreendida pelo setor privado.

Levcovitz E 1997. Transição x consolidação: o dilema estratégico da construção. Tese de doutorado. Instituto de Medicina Social/UERJ.

Mendes E V 1996. Uma agenda para a saúde. Hucitec, São Paulo.

Piola S \& Biasoto Jr G 2001. Financiamento do SUS nos anos 90. Brasil: radiografia da saúde. Unicamp, Campinas.

Reis C 1997. O setor privado "autônomo": um caso de política. In Série Estudos em Saúde Coletiva, n. 152, IMS/ UERJ, Rio de Janeiro.

Senna M \& Souza R. A municipalização e os novos desafios à gestão local de saúde. Revista Em Pauta, FSS/ UERJ (no prelo).

Visor Ipea, Ano III, n. 7, novembro de 1998.

Artigo apresentado em15/6/2002

Versão final apresentada em 18/8/2002

Aprovado em 21/8/2002 